\title{
Forty-five degree cutting septoplasty
}

\author{
Yen-Chang Hsiao MD¹, Chun-Shin Chang MD¹, Shiow-Shuh Chuang MD¹, \\ Georgios Kolios MD², Mohamed Abdelrahman MD',3
}

\begin{abstract}
Y-C Hsiao, C-S Chang, S-S Chuang, G Kolios, M Abdelrahman. Forty-five degree cutting septoplasty. Plast Surg 2016;24(3):199-203.
\end{abstract}

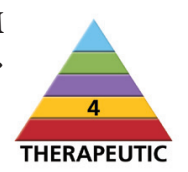

BACKGROUND: The crooked nose represents a challenge for rhinoplasty surgeons, and many methods have been proposed for management; however, there is no ideal method for treatment. Accordingly, the $45^{\circ}$ cutting septoplasty technique, which involves a $45^{\circ}$ cut at the junction of the L-shaped strut and repositioning it to achieve a straight septum is proposed.

METHODS: From October 2010 to September 2014, 43 patients underwent the $45^{\circ}$ cutting septoplasty technique. There were 28 men and 15 women, with ages ranging from 20 to 58 years (mean, 33 years). Standardized photographs were obtained at every visit. Established photogrammetric parameters were used to describe the degree of correction: Correction rate $=$ (preoperative total deviation - postoperative residual deviation)/preoperative total deviation $\times 100 \%$ was proposed.

RESULTS: The mean follow-up period for all patients was 12.3 months. The mean preoperative deviation was $64.3^{\circ}$ and the mean postoperative deviation was $2.7^{\circ}$; the overall correction rate was $95.8 \%$. One patient experienced composite implant deviation two weeks postoperatively and underwent revision rhinoplasty. There were no infections, hematomas or postoperative bleeding.

CONCLUSION: Based on the clinical observation of all patients during the follow-up period, the $45^{\circ}$ cutting septoplasty technique was shown to be effective for the treatment of crooked nose.

\section{La septoplastie par incision à quarante-cinq degrés}

HISTORIQUE : Le nez aquilin est un défi pour les chirurgiens en rhinoplastie. De nombreuses méthodes de prise en charge ont été proposées, mais il n'existe pas de solution thérapeutique idéale. La technique de septoplastie par incision à $45^{\circ}$ est pratiquée à la jonction de l'étai en $\mathrm{L}$, qui est repositionné pour redresser la cloison nasale.

MÉTHODOLOGIE : D'octobre 2010 à septembre 2014, 43 patients ont subi une septoplastie par incision à $45^{\circ}$. Il s'agissait de 28 hommes et de 15 femmes de 20 à 58 ans (moyenne de 33 ans). Les chercheurs ont pris des photos standardisées à chaque visite. Ils ont utilisé les paramètres de photogrammétrie établis pour décrire le degré de correction. Ils ont proposé que le taux de correction $=$ (déviation préopératoire totale - déviation résiduelle postopératoire)/déviation préopératoire totale $\times 100 \%$.

RÉSULTATS : Tous les patients ont été suivis en moyenne 12,3 mois. Ils avaient une déviation préopératoire moyenne de $64,3^{\circ}$ et une déviation postopératoire moyenne de $2,7^{\circ}$, pour un taux de correction global de 95,8\%. Un patient a présenté une déviation composite de l'implant deux semaines après l'opération et a subi une rhinoplastie de révision. Il n'y a pas eu d'infections, d'hématomes ni d'hémorragies postopératoires.

CONCLUSION : D'après l'observation clinique de tous les patients pendant la période de suivi, la septoplastie par incision à $45^{\circ}$ est efficace pour corriger un nez aquilin.

Key Words: Crooked nose; Rhinoplasty; Septal deviation; Septoplasty

$\mathrm{T}$ he correction of a crooked or twisted nose is a challenge for the rhinoplasty surgeon. It results from a complex deformity of the bony pyramid, the upper and lower cartilaginous vaults and the septum, and causes functional and aesthetic problems. With respect to the median axis, the deviation of the nose may be linear, C-shaped or S-shaped, which represents a challenging deformity.

The forces of scar contracture, as well as both cartilage thickening and deformation, may make the deviated nose resistant to conventional surgical interventions, thus leading to the recurrences (1-5).

To obtain satisfactory aesthetic and functional results, a rhinoplasty surgeon requires a complete understanding of the three-dimensional pathology, nasal anatomy and physiology, as well as accurate preoperative analysis. Preoperative discussion with the patient is important to explain that it is very difficult to get the nose perfectly straight.

Additionally, a thorough understanding of the physiology of cartilage and its healing, as well as the ability to precisely execute the surgical steps necessary for altering and controlling the nasal septum to prevent recurrences, is required $(3,6,7)$.

There is no ideal single surgical technique for the correction of the crooked nose. The surgical techniques normally used can prove to be unsuccessful as a result of either recurrence or collapse of the excessively weakened dorsal cartilage. Recurrence and airway obstruction risks are high because of cartilage memory, scar contracture or collapse of the excessively weakened nasal dorsum. Correction of septal deviation and maintenance of the correction are the key elements in the surgical management of the crooked nose. Numerous techniques for achieving this have been described (2,8-12).

A review of the literature suggests there are three surgical procedures that are primarily used for the treatment of crooked nose:

camouflage techniques, complete reconstruction, anatomic reconstruction or a combination thereof.

In the present article, we present a different technique for the treatment of patients with crooked noses $-45^{\circ}$ cutting septoplasty which includes $45^{\circ}$ cutting at the junction of the L-shaped strut and repositioning them to obtain a straight septum.

\section{METHODS}

From October 2010 to September 2014, 43 patients underwent the $45^{\circ}$ cutting septoplasty procedure. There were 28 men and 15 women, with ages ranging from 20 to 58 years (mean age 33 years). Patients' nasal profiles were documented and photographed both preoperatively and postoperatively. Efforts were made to ensure true profile views were obtained by the use of paper tape at $0^{\circ}, 45^{\circ}, 90^{\circ}, 135^{\circ}$ and $180^{\circ}$, with the camera lens at $90^{\circ}$ from a rotating stool. Patients were asked to look straight ahead with their eyes in the neutral position.

\section{Photogrammetric evaluation}

Preoperative and postoperative photographs were analyzed using the Adobe Photoshop CS6 measure tool (Adobe Systems, Inc, USA). Landmarks used in the frontal view were pupil reflex points (PRP). The PRP were marked and a line was drawn between them using Photoshop. A vertical line was drawn based on the PRP axis. The start point of evaluation was at the keystone, the junction at the nasal bone and septum to exclude the nasal bone deviation. Each deviation from the keystone to the nasal tip were drawn and measured (in degrees). The overall deviated degrees were accumulated preoperatively and postoperatively. To better analyze the correction of crooked nose, the authors devised a photogrammetric parameter.

${ }^{1}$ Department of Plastic and Reconstructive Surgery, Chang Gung Memorial Hospital, College of Medicine, Chang Gung University, Taipei, Taiwan

${ }^{2}$ Department of Plastic and Reconstructive Surgery, Agaplesion Diakonie Klinikum Hamburg, Germany; ${ }^{3}$ University of Khartoum, Sudan.

Correspondence: Dr Mohamed Abdelrahman, Department of Plastic and Reconstructive Surgery, Chang Gung Memorial Hospital, 5, Fu-Hsing

Street, Kweishan, Taoyuan 333, Taiwan. Telephone 886-3-3281200 ext 3355,fax 886-3-3287260, e-mail nosehsiao@gmail.com 


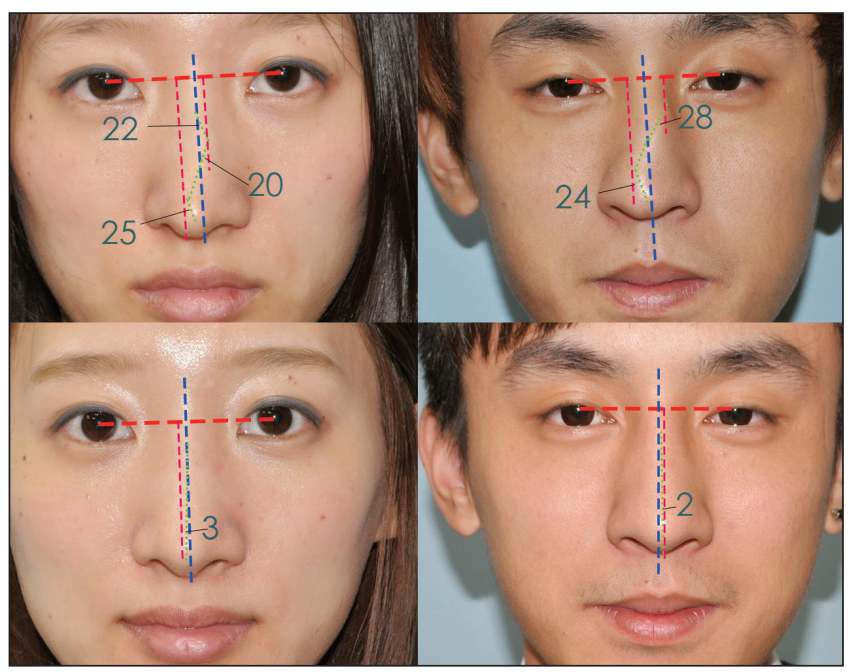

Figure 1) The pupil reflex points (PRP) were marked and a line was drawn between them using Photoshop (Adobe Inc, USA) (red dashed line). A vertical line was drawn based on the PRP axis (blue dashed line). The start point of evaluation was at the keystone, the junction at the nasal bone and septum to exclude the nasal bone deviation. Each deviation from the keystone to the nasal tip were drawn and measured in degrees (green dashed line). The overall deviated degrees were assessed preoperatively and postoperatively.

Correction rate $=($ Preoperative total deviation - postoperative residual deviation) / preoperative total deviation $\times 100 \%$.

Left: This woman's preoperative deviation was $67^{\circ}$; postoperative deviation was $3^{\circ}$; and the correction rate was $95.5 \%$. Right: This man's preoperative deviation was $52^{\circ}$; postoperative deviation was $2^{\circ}$; and the correction rate was $96.15 \%$

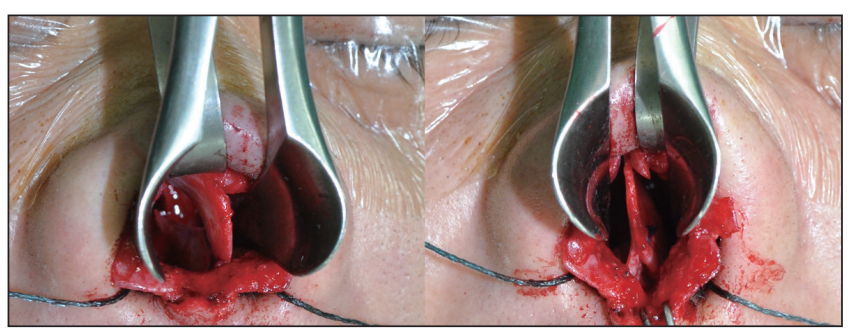

Figure 2) Left $A 45^{\circ}$ cutting at the junction between the dorsal and caudal septum. Right Reorientation of the dorsal strut to left side of the caudal strut to achieve a straight dorsum

\section{Correction rate $=$ (Preoperative total deviation - postoperative residual deviation) / preoperative total deviation $\times 100 \%$ (Figure 1 )}

\section{Surgical technique}

Surgery was performed via an external open rhinoplasty approach. Nasal dissection was performed in a standard fashion. Subpericondrial degloving was followed by resection of posterio-inferior deviated septal cartilage. Then, at least $1 \mathrm{~cm}$ dorsal and caudal septal struts (L-shaped strut) were preserved. Meanwhile, deviated septal segments, including the perpendicular plate of the ethmoid and vomer plate were removed. Extramucosal division of the upper lateral cartilage from the dorsal septum was performed to minimize the deforming forces and reorient the dorsal septal strut into a straight position and create pockets for spreader graft insertion. Both aggressive dissection to the nasal spine of maxilla bone and detachment of the base of the caudal septum from the nasal spine were unnecessary. In the case of a deviated bony pyramid, medial and lateral osteotomies were undertaken

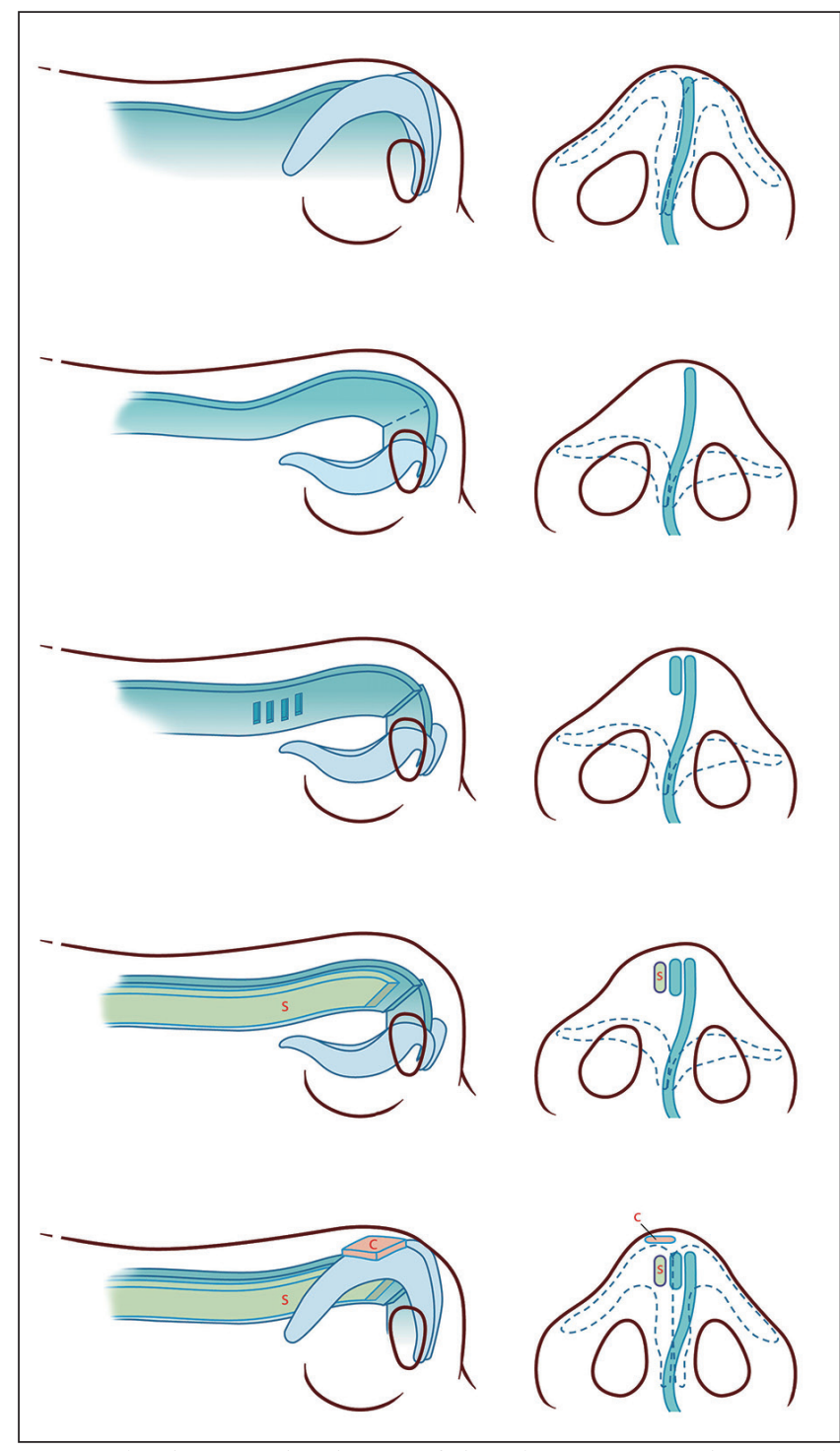

Figure 3) The surgical technique of the $45^{\circ}$ cutting septoplasty (top). Nasal dissection via an open rhinoplasty (top, second). Resection of posterio-inferior deviated septal cartilage and performing a $45^{\circ}$ septoplasty (centre). Reorientation of the dorsal strut to right side of the caudal strut and performing scoring technique at the dorsal strut (below, second). A combination procedure: right unilateral spreader graft (bottom) A combination procedure: right camouflage cap graft

before septoplasty. If a dorsal hump was present, a humpectomy plus lateral osteotomies (rarely performed medial osteotomies) were also performed before that. After correction of the bony deviation, a $45^{\circ}$ cutting septoplasty was performed. An oblique cut was made at the junction between the dorsal and caudal septum (angle septum), which divided the L-shaped septum into the dorsal strut and caudal strut (Figure 2). Subsequently, a detailed intraoperative assessment was performed to evaluate the trend of septal deviation. If the dorsal strut was deviated to the left, then the dorsal strut was intentionally repositioned to right side of the caudal strut (Figure 3). In contrast, if the dorsal strut was deviated to the right, then the dorsal strut was reoriented to left side of the caudal strut to achieve a straight dorsum (Figure 4). The dorsal and caudal struts were overlapped and fixed together using 5-0 polypropylene sutures. A unilateral spreader graft was used at the concave side of the dorsal septum to widen the internal valve and supply the volume deficiency at the middle vault. In certain cases, bilateral spreader grafts were used for reinforcement of the straight configuration of the dorsal septum and to correct the 


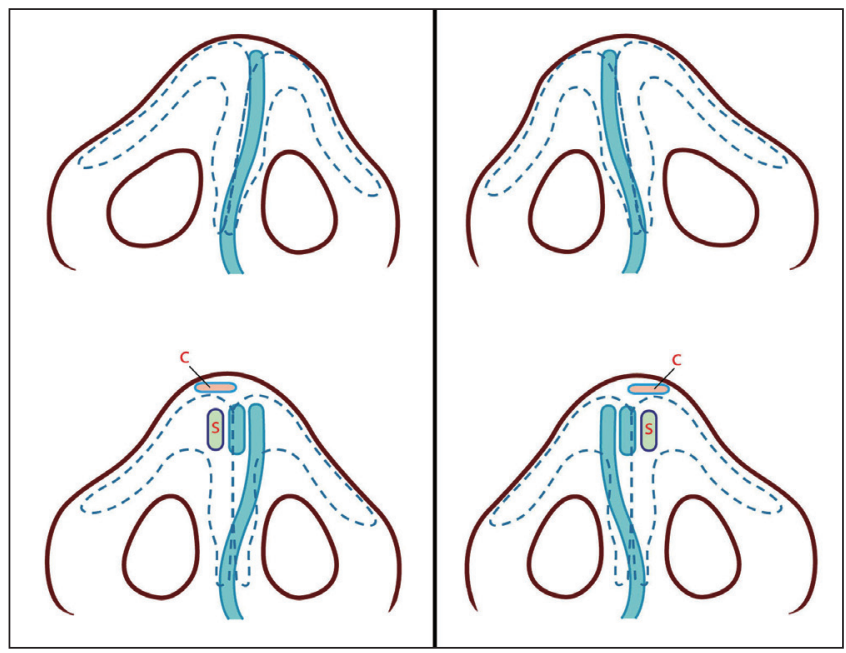

Figure 4) Left If the dorsal strut is deviated to the left, then the dorsal strut is reoriented to right side of the caudal strut. The right spreader graft and the right camouflage cap graft are built as combination procedures. Right If the dorsal strut is deviated to the right, then the dorsal strut is reoriented to left side of the caudal strut. The left spreader graft and the left camouflage cap graft are built as combination procedures

\section{TABLE 1}

\section{Combination procedures}

\begin{tabular}{lcccc}
\hline & $\begin{array}{c}\text { Camouflage } \\
\text { cap graft }\end{array}$ & $\begin{array}{c}\text { Spreader } \\
\text { Graft }\end{array}$ & Scoring & $\begin{array}{c}\text { Osteotomies } \pm \\
\text { humpectomy }\end{array}$ \\
\hline Patients, $\mathrm{n}$ & 19 & 23 & 35 & 26 \\
\hline
\end{tabular}

possibility of nasal valve block at the side of the deviation. Spreader grafts also compensate for the risk of a weakening effect at the junction of the two struts after applying the $45^{\circ}$ cutting septoplasty manoeuvre. Other concomitant procedures may be peformed with a $45^{\circ}$ cutting septoplasty simultaneously including scoring and camouflage cap grafts. A scoring technique involves making multiple weakening incisions at the convex side of the cartilage to release tension and achieve straightening. Breaking the cartilaginous continuity or weakening of the cartilage should, however, be performed with caution. Spreader grafts can also compensate for the above side effects. Camouflage cap grafts were used in certain patients if any residual tip deviation presented. Cap grafts were intentionally placed at the contralateral side of the orientation of the deviated tip. Then the mucopericondrial flaps were closed using 4-0 sutures (Chromic, Hu Friedy, USA). The open rhinoplasty incisions were closed in the standard fashion. Intranasal packs were inserted and could be removed one day after surgery. If osteotomies were performed, the intranasal packs were kept for seven days.

\section{RESULTS}

The follow-up period for all patients was between six and 39 months (mean 12.3 months). Twenty-six patients underwent either medial and lateral osteotomies, or humpectomies and lateral osteotomies to correct bony pyramid deviations or dorsal humps. All patients underwent varied concomitant procedures: 19 had camouflage cap grafts; and 23 had spreader grafts. Thirty-five patients underwent dorsal septal strut scoring (Table 1 ). The mean preoperative deviation was $64.3^{\circ}$; the mean postoperative deviation was $2.7^{\circ}$; and the mean correction rate was $95.8 \%$. One patient experienced composite implant deviation two weeks postoperatively and underwent revision rhinoplasty. None of them experienced infection, hematoma or bleeding postoperatively (Figures 5 to 7 ).

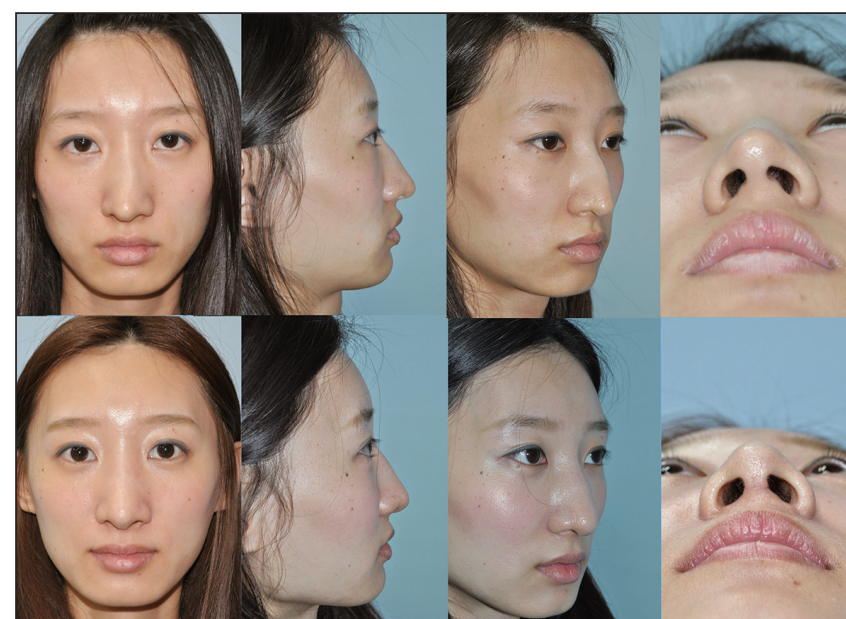

Figure 5) A 26-year-old woman sustained a previous nasal injury that resulted in a crooked nose. Preoperative views revealed the crooked nasal deformity; the S- shaped deviated septum was examined intranasally. Open rhinoplasty was performed. The deviated inferior-posterior septum and septal bone were removed. Medial and lateral osteotomies were performed to correct a deviated nasal pyramid. A $45^{\circ}$ cutting septoplasty was performed. A dorsal septal strut was repositioned on the left side of the caudal septal strut. Right side spreader grafts, the columella strut and the camouflage left cap graft were placed. The postoperative photographs show the nasal profile 11 months after surgery. Top left Preoperative frontal view. Lower left Postoperative frontal view after 11 months. Top left, second Preoperative right lateral view. Lower left second Postoperative right lateral view after 11 months. Top left, third Preoperative right $45^{\circ}$ view. Lower left, third Postoperative right $45^{\circ}$ view after 11 months. Top right Preoperative basal view. Lower right Postoperative basal view after 11 months

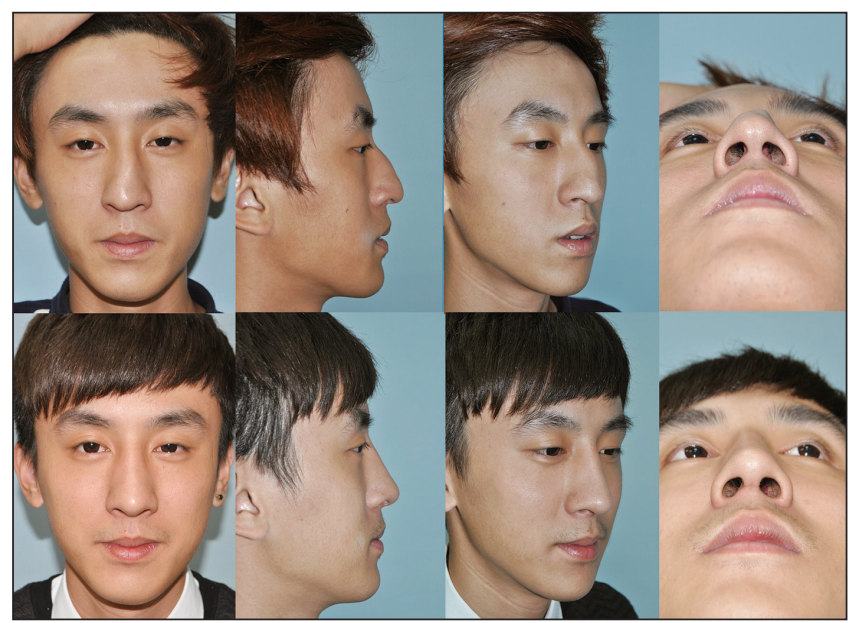

Figure 6) A 28-year-old man presented with a crooked nose. A left side nasal bone deviation, dorsal hump and a S-shaped septal deviation were diagnosed preoperatively. Medial and lateral osteotomies were performed. Removal of the deviated septum and bone was followed by a $45^{\circ}$ cutting septoplasty. A dorsal septal strut was placed to the left side of the caudal septal strut. The left side unilateral spreader graft and the camouflage left cap graft were built using septal cartilage. The postoperative photographs show the nasal profile eight months after surgery. Top left Preoperative frontal view. Bottom left Postoperative frontal view after eight months. Top left, second Preoperative left lateral view. Lower left, second Postoperative left lateral view after eight months. Top left, third Preoperative right $45^{\circ}$ view. Lower left, third Postoperative right $45^{\circ}$ view after eight months. Top right Preoperative basal view. Lower right Postoperative basal view after eight months 


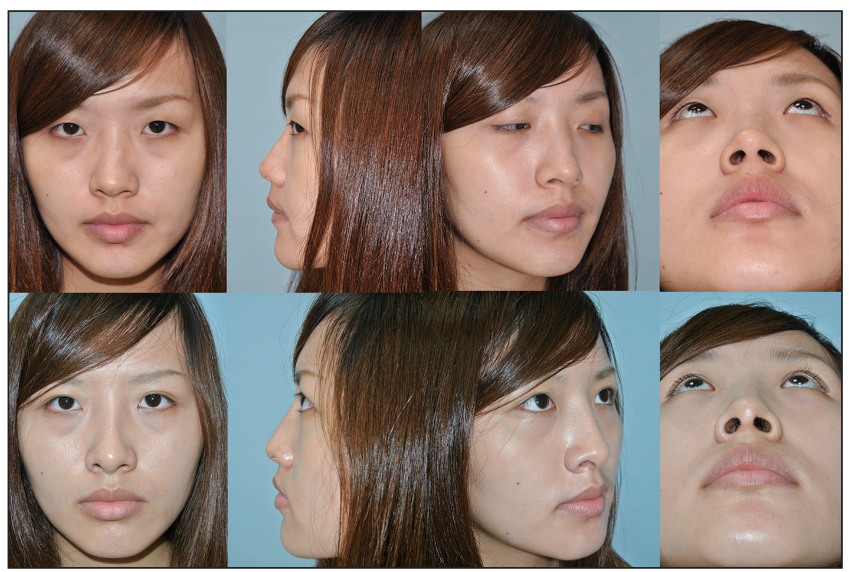

Figure 7) A 22-year-old woman presented with a crooked nose due to a nasal injury in childhood. The nasal pyramid was deviated to the left and a S-shaped septal deviation was diagnosed preoperatively. The nasal pyramid was corrected using medial and lateral osteotomies. After removing the deviated septum and septal bone, a $45^{\circ}$ cutting septoplasty was performed, and a dorsal septal strut was placed to the left of the caudal septal strut. Scoring was performed at the convex side of the dorsal septal strut. The left side unilateral spreader graft was built using the septum. Finally, the left side camouflage cap was built using ear cartilage. The postoperative photographs show the nasal profile 13 months after surgery. Upper left Preoperative frontal view. Lower left Postoperative frontal view after 13 months. Top left, second Preoperative left lateral view. Lower left, second Postoperative left lateral view after 13 months. Top left, third Preoperative right $45^{\circ}$ view. Lower left, third Postoperative right $45^{\circ}$ view after 13 months. Top right Preoperative basal view. Lower right Postoperative basal view after 13 months

\section{DISCUSSION}

The term 'crooked nose' is commonly used for all clinical conditions involving deviation of the nasal pyramid from the median line. This pathology is frequently found in clinical practice today as the result of blunt trauma from sports or motor vehicle accidents. Still more important than the social aspect of the crooked nose is its psychological impact on the individual.

Despite the many techniques proposed for the management of crooked nose, it remains one of the most difficult problems encoutered by rhinoplasty surgeons. It needs a careful preoperative assessment as well as tedious steps of surgical execution to achieve optimum results $(2,6,8,9,13,14)$.

Correction of the deviated septum represents the cornerstone of the management of crooked nose. Progress in surgical rhinoplasty techniques has made it possible to use procedures that are more radical than in the past such as the correction of septal deformity and corrective rhinoplasty performed in one procedure. This is capable of eliminating the most common complications, such as insufficient treatment, structural weakening and relapse $(12,13,15-17)$. However, the risk for recurrence remains because of the strong 'elastic memory' of the cartilage, which tends to return the septum to its original preoperative position and avoid any undue weakening of the structure resulting in collapse of the nasal dorsum. The bony structures of the nasal pyramid also involved in the deviation remain in their new position once they have been repositioned in the centre. To correct the deformity, the extrinsic forces must be released, and the intrinsic forces must be overcome by weakening the cartilage or by overpowering the deforming forces using sutures or grafts $(1,7,9,18)$.

One of the most important factors in the etiology of septal deviation is a relative overgrowth of septal cartilage compared with its bony frame. This disproportion creates an intrinsic stress that results in bending and buckling of the cartilage. This intrinsic stress should be broken and released in some cases to obtain a straight septum. The
L-strut is still bound to the bony frame at two points of fixation at the ethmoid posterosuperiorly and anterior nasal spine anterioinferiorly. Classically, one of these fixation points should be released and reset to eliminate the intrinsic stress resulting from a relatively tight bony frame. This is usually accomplished at the anterior nasal spine by releasing, shortening and resetting the caudal septal strut. However, it can also be achieved at the ethmoid septal cartilage junction in certain cases. Our technique provides a third option for the release of intrinsic stress, leaving both bony interfaces intact.

Our new proposed technique $-45^{\circ}$ cutting septoplasty - has worked well in all patients we have used it for, and has avoided the drawbacks of other techniques.

An extended dissection to the columella base is not required, compared with the extensive dissection required in the 'swinging door' technique and its modifications $(12,13)$. While a deviated nasal septum can, in fact, be largely removed from a functional standpoint, it is necessary in any case to leave an L-shaped structure capable of supporting the nasal pyramid as a whole. This cannot be corrected well in other methods such as the 'swinging door' technique; however, effective correction can be achieved by using a $45^{\circ}$ cutting septoplasty.

One technique offering good results involves extracorporeal reshaping of the nasal septum and insetting it back onto the nasal pyramid (19). However, it has the disadvantages of septal cartilage weakening, resorption and loss of natural support of the surrounding structures, while in $45^{\circ}$ cutting septoplasty, there is no septal cartilage loss, especially with the minimal septal height loss because we cut at a $45^{\circ}$ junction, which guards against the risk for mobility. In addition, in the $45^{\circ}$ cutting method, there is an overlap part at the septal angle, which can also correct excessive caudal septum in a deviated nose without removing it. Furthermore, $45^{\circ}$ cutting is better than vertical cutting at the dorsal strut and horizontal cutting at the caudal strut, which may lose more tip length and tip projection respectively, if overlap fashion of the divided strut is applied. In contrast, the $45^{\circ}$ cutting spetoplasty results in a balanced decrease of tip projection as well as tip length and, above all, a minimal distortion can be corrected easier than the other two techniques'.

One of the widely used methods for crooked nose treatment is the spreader graft with different modifications (2,20-22), which involves placement of a rectangular strip of cartilage on either side of the deviated septum. It also proved immediately useful in functional terms by broadening the angle of the internal nasal valve and, thus, increasing respiratory airflow. However, spreader grafts are not an ideal and effective means of straightening a deviated dorsal septum, but can be applied in certain scenarios to improve nasal valve obstruction.

The scoring technique involves making multiple weakening incisions at the cartilage to release tension and achieve straightening. Similar to spreader grafts, it is difficult to achieve complete correction using a single method.

The $45^{\circ}$ cutting septoplasty method is easy to learn and not technically demanding and, once the rhinoplasty surgeon becomes accustomed to it, it can easily performed intranasally. It can easily be combined with other methods of crooked nose management; for example, it can be freely used in combination with a spreader graft on one side of the septum depending on the deviations. It can also be used with the scoring method, camouflage grafts, etc.

The $45^{\circ}$ cutting septoplasty, however, has some disadvantages. Minimal decreasing tip projection foreshortens the dorsum, and tip cephalical rotation may occur after this manoeuvre. In addition, a suture at the junction of the $45^{\circ}$ cutting line is needed, which will cause a loss of support at the septal angle. However, it can easily be compensated for by the bilateral spreader grafts. The missing tip projection also can be corrected by the camouflage cap graft. Alternatively, the possibility of decreased length and projection can also be minimized by reconstruction using bilateral spreader grafts by splinting the divided L-shaped strut placed in an end-to-end fashion.

Although the $45^{\circ}$ cutting septoplasty can correct the upper part of the malposition of the caudal septum by intentional reposition of the 
dorsal strut and caudal strut, the base of the caudal septum sometimes reveals insufficient correction. Therefore, if the patient has a severely deviated basal caudal septum, other techniques, such as the 'swing door', should be applied to correct it.

The present study had one primary limitation: no objective functional analysis was performed. The airway study should be included in consequent studies. However, the technique will be of great value to the community of practice.

No single technique can correct the crooked nose perfectly. However, the $45^{\circ}$ septoplasty method, combined with other methods, can achieve not only functional, but also aesthetic improvement in crooked nose corrections.

\section{REFERENCES}

1. Byrd HS, Salomon J, Flood J. Correction of the crooked nose. Plastic and reconstructive surgery 1998;102:2148-57.

2. Boccieri A, Pascali M. Septal crossbar graft for the correction of the crooked nose. Plast Reconstr Surg 2003;111:629-38.

3. Porter JP, Toriumi DM. Surgical techniques for management of the crooked nose. Aesth Plast Surg 2002;(26 Suppl 1):S18.

4. Gurlek A, Ersoz-Ozturk A, Celik M, Firat C, Aslan S, Aydogan H. Correction of the crooked nose using custom-made high-density porous polyethylene extended spreader grafts. Aesth Plast Surg 2006;30:141-9.

5. Emsen IM. A different approach to the reconstruction of the stubborn crooked nose with a different spreader graft: Nasal bone grafts harvested from the removed nasal hump. Aesthetic Plast Surg 2008;32:266-73.

6. Fry H. Nasal skeletal trauma and the interlocked stresses of the nasal septal cartilage. Br J Plast Surg 1967;20:146-58.

7. Courtiss EH. Septorhinoplasty of the traumatically deformed nose. Ann Plast Surg 1978;1:443-9.

8. Mendelsohn M. Straightening the crooked middle third of the nose: Using porous polyethylene extended spreader grafts. Arch Facial Plast Surg 2005; 7:74-80.

9. Pontius AT, Leach JL Jr. New techniques for management of the crooked nose. Arch Facial Plast Surg 2004;6:263-6.

10. Rohrich RJ, Gunter JP, Deuber MA, Adams WP Jr. The deviated nose: Optimizing results using a simplified classification and algorithmic approach. Plast Reconstr Surg 2002;110:1509-1523.

11. Okur E, Yildirim I, Aydogan B, Akif Kilic M. Outcome of surgery for crooked nose: An objective method of evaluation. Aesth Plast Surg 2004;28:203-7.

\section{CONCLUSION}

The crooked nose remains one of the most difficult problems, even to expert nasal surgeons. The $45^{\circ}$ cutting septoplasty technique will offer satisfactory and long-lasting results; however, as in any other rhinoplasty problems, it will yield excellent results when combined with other procedures.

DISCLOSURES: The authors have no financial disclosures or conflicts of interest to declare.

12. Seltzer AP. The nasal septum: Plastic repair of the deviated septum associated with a deflected tip. Arch Otolaryngology 1944;40:433-44.

13. Metzenbaum M. Replacement of the lower end of the dislocated septal cartilage versus submucous resection of the dislocated end of the septal cartilage. Arch Otolaryngol1929;9:282-96.

14. Boccieri A. The crooked nose. Acta otorhinolaryngologica Italica 2013:33:163-8

15. Salinger S. Deviation of the septum in relation to the twisted nose. Arch Otolaryngol1939;29:520-32.

16. Sykes JM, Kim JE, Shaye D, Boccieri A. The importance of the nasal septum in the deviated nose. Facial Plast Surg 2011;27:413-21.

17. Constantine FC, Ahmad J, Geissler P, Rohrich RJ. Simplifying the management of caudal septal deviation in rhinoplasty. Plast Reconstr Surg 2014;134:379e-388e.

18. Barsky AJ, Simon E. Principles and practice of plastic surgery, 2nd edn. New York: McGraw-Hill Book Company; 1964.

19. Gubisch W. The extracorporeal septum plasty: A technique to correct difficult nasal deformities. Plast Reconstr Surg 1995;95:672-82.

20. Sheen JH. Spreader graft: A method of reconstructing the roof of the middle nasal vault following rhinoplasty. Plast Reconstr Surg 1984;73:230-9

21. Rohrich RJ, Hollier LH. Use of spreader grafts in the external approach to rhinoplasty. Clin Plastic Surg 1996;23:255-62.

22. Toriumi DM, Ries WR. Innovative surgical management of the crooked nose. Fac Plast Surg Clin 1993;1:63-78. 